\title{
INFLUENCE OF ROLLING ON BEHAVIOUR OF POLYSTYRENE FILMS
}

\author{
Anatoliy Aleksandrovich Olkhov \\ Candidate of Technical Sciences, Associate Professor, Senior Researcher, \\ Laboratory of Prospective Compositional Materials and Technologies, \\ Russian University of Economics named after G.V. Plekhanov \\ aolkhov72@yandex.ru \\ Stremyanny Pass., 36, 117997 Moscow, Russian Federation
}

\begin{abstract}
The effect of cold rolling of the isotropic and preliminary oriented polystyrene films on their properties has been investigated. It was found that the film modification by the cold rolling is necessary to conduct for only the isotropic films but not for the oriented ones. To achieve the optimal state of rolling and to reduce the side stresses at drawing, the process should be performed in several consecutive stages.

Key words: cold rolling, isotropic polystyrene films, oriented polystyrene films, mechanical parameters, optimal state of rolling.
\end{abstract}

\section{Introduction}

It is known that the main deficiency of the films made from the block atactic polystyrene (PS) is their brittleness and low strength [1]. This deficiency of the films to some extent can be improved after their oriented rolling. One of the ways of enhancing the film mechanical properties is modification of its structure by rolling of the film between rolls at temperatures below the glass transition temperature. This way was successfully applied for the polyethyleneterephthalate (PET), polyamide and blend films [2-6].

The goal of this work was to investigate the effect of the cold rolling on the strain properties of the isotropic and consecutively oriented and $\because$ already oriented films.

\section{Experimental}

The investigations were conducted on PS films (type ПCM-115 Russia) obtained by the extrusion of the polymer melt on the cold drum surface. The thickness of the isotropic films was $300 \mu \mathrm{k}$. The initial samples had a small value of the double light refraction $(\Delta n)$ and the heat set in the prolonged direction less than $3 \%$.

A portion of the isotropic films underwent rolling at room temperature with a constant rate between rolls having different gap between their surfaces. The maximal value of the gap was equal to the film thickness. In the course of rolling, the gap forces were measured. At rolling with the gap lower than the film thickness, the irreversible deformation took place - the film was extended in the prolonged direction $\left(\lambda_{n}\right)$. The stresses at rolling $\left(\sigma_{r}\right)$ were calculated based on the gap forces per unit of the film width and the length of the contact of the roll and film which was measured taking into account the angle of the polymer covering the roll. It was assumed that all the stress is distributed uniformly along the film width and the contact with roll length.

The deformation along the film thickness was accepted to be equal to the deformation in the prolonged direction $\left(\lambda_{n}\right)$ not taking into account 


\section{ТЕХНИКО-ТЕХНОЛОГИЧЕСКИЕ ИННОВАЦИИ}

the elastic component (reversible) which recovered along the thickness after the film left the gap between the rolls. By changing the gap, the film thickness and $\lambda_{n}$ are changed also. The compression stress $\left(\sigma_{\text {com }}\right)$ and the tensile strength $\left(\sigma_{\rho}\right)$ of the films depending on the film deformation at room temperature were determined according to the corresponding standard procedures (GOST 11262-80, Russia). Portion of the isotropic and drawn films underwent the uniaxial orientation at $100{ }^{\circ} \mathrm{C}$ and $200 \% /$ min to different relative lengths $(\lambda)$. The total extension of the drawn films was $\left(\lambda \times \lambda_{n}\right)$. Portion of the undrawn and uniaxially oriented films underwent the cold rolling.

The mechanical properties of all samples were evaluated according to the standard procedures (GOST 11262-80, Russia).

\section{Results and Discussion}

The effect of the state of film extension at cold rolling on their tensile strength $\left(\sigma_{\rho}\right)$ and the elongation at break $\left(\varepsilon_{\rho}\right)$ is shown in Fig. 1 and Fig. 2 (curve 1).

From the presented data, it is seen that $\sigma_{\rho}$ is slightly increased with the $\lambda_{n}$ increase till 1.41.5 what is related to the accumulation of certain oriented molecular chains. This is supported by increasing of the double light refraction, $\Delta \mathrm{n}$, till $347 \cdot 0^{-3}$. The further $\lambda_{n}$ increase $\left(\lambda_{n}>1,6\right)$ till 2,0 leads to the $\sigma_{\mathrm{p}}$ decrease what is related to the occurring of the side effect: the longitudinal splitting of the film on fibers. Although the process is accompanied by the $\Delta \mathrm{n}$ increase, the tensile strength is sharply reduced and the film loses its monolithic state.

As it is seen from Fig. 2, $\varepsilon_{\rho}$ continuously increases with the $\lambda$, increase even so that some fragments of the split films are ruptured at significantly higher values of $\varepsilon_{\rho}$ than the original monolithic film. The density of the films with different $\lambda_{n}$ is practically the same. This means that along with the thermoplastics tendency to increase density with the orientation at rolling, at rolling of PS, the reversed process leading to the density decrease takes place.

The two processes compensate each other. At PS rolling, the compressing and shearing polymer deformations lead to rupture of the overstressed bonds between the segments and to relaxation of the residual stresses. As the result, the deformation ability of the drawn films increases (Fig. 2, curve 1). This is confirmed by the change of the glass transition temperature ( $\mathrm{Tg}$ ). If the original samples had the $\mathrm{Tg}=92$ $97{ }^{\circ} \mathrm{C}$, the samples after rolling till $\lambda_{n}=1.4$ had the $\mathrm{Tg}$ decreased to $60-65^{\circ} \mathrm{C}$. Such picture was also found for the PET samples [6].

The mentioned above modification of the PS structure should provide the better orientational rolling of the films.

As it is seen from Fig. 1 and 2, at the same value of the total rolling $\left(\lambda \times \lambda_{n}\right)$ of the rolltreated and not treated films, the $\sigma_{\rho}$ of the first

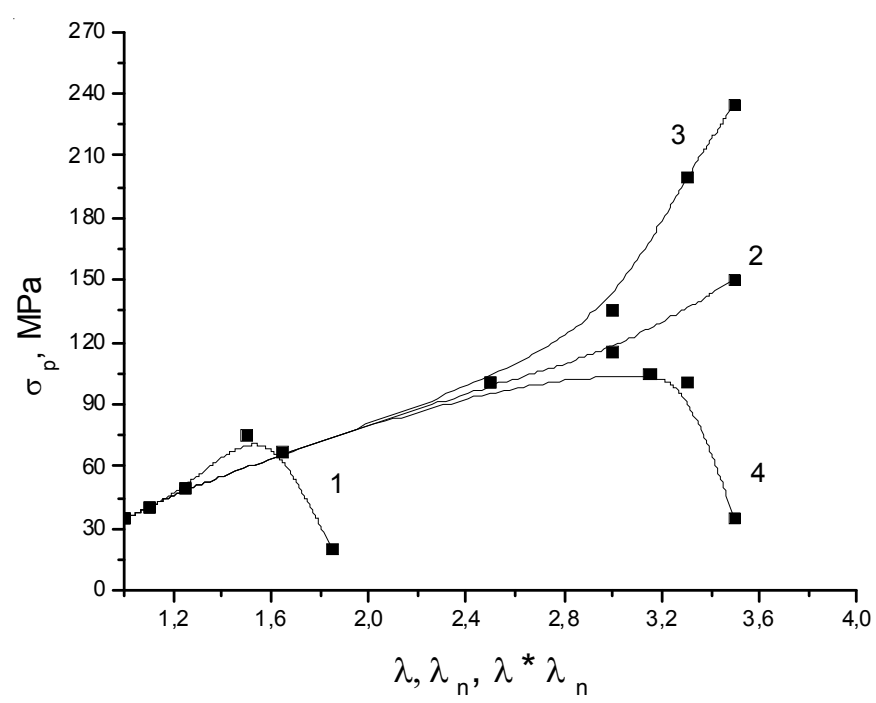

Fig. 1. Dependence of tensile strength, $\sigma_{\rho}$, on the elongation at rolling, $\lambda_{n}(1)$; at orientation, $\lambda$, (2); at orientation of the drawn films, $\lambda \times \lambda_{n}$ (3); and at rolling of the oriented films $\lambda^{n} \times \lambda_{n}$ (4). Temperature is $100{ }^{\circ} \mathrm{C}$. The rate of the orientational rolling is $200 \% / \mathrm{min}$. The $\lambda$ for curves 3 and 4 is 2.5 


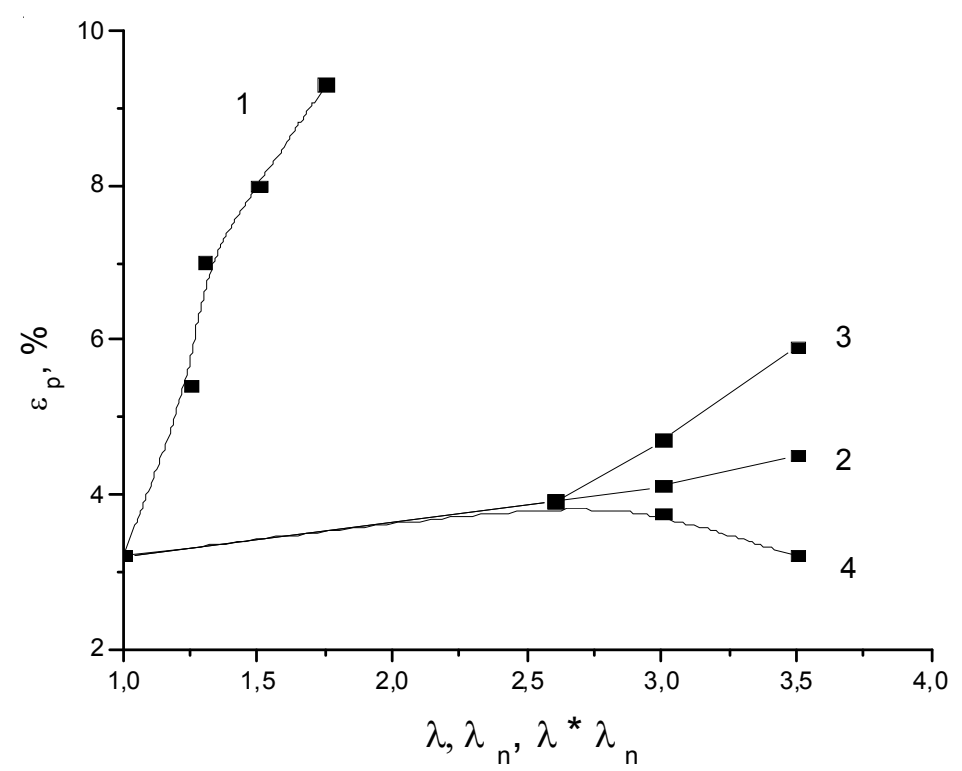

Fig. 2. Dependence of the elongation at break, $\varepsilon_{\rho}$ on $\lambda, \lambda_{n}$ and $\lambda \times \lambda_{n}$. The notations are the same as on Fig. 1

ones are significantly higher of the $\sigma_{\rho}$ of the just oriented films especially at the high values of $\lambda \times \lambda_{n}$. The change of $\Delta n$ is completely coincides with the change of $\sigma_{\rho}$ of the films. So, at $\lambda \times \lambda_{n}=3.5$, the $\Delta n$ is $\sim 0.12$ for the preliminary roll-treated films and 0.08 for the oriented without roll-treated films, end so on. The density of the same samples is 1.09 and $1.06 \mathrm{~g} / \mathrm{cm}^{3}$ correspondingly.

At the same time, the $\varepsilon$ of the only oriented films reduces to $\lambda=2.7-3.0$ but the parameter for the preliminary roll-treated is even higher what is unusual (Fig. 2, curves 2 and 3 ). The Tg of the films extended to $\lambda=2.5$ is $95-97^{\circ} \mathrm{C}$, and $\mathrm{Tg}$ of the preliminary roll-treated films with $\lambda \times \lambda_{n}=3.5$ is significantly lower: $82-85^{\circ} \mathrm{C}$. This means that even for the highly oriented films, the preliminary roll-treatment provides the greater chain mobility compared with the oriented samples without roll-treatment Naturally, the orientation in the drawn films shifts the $\mathrm{Tg}$ toward the higher values compared with the original samples. From this point of view, it is interesting to compare data on the effect of rolltreatment on the already orientated films (Fig. 1 and 2, curve 4).

From the data it can be concluded that beginning from the $\lambda \times \lambda_{n}=3.5$, the cold drawing leads to the $\sigma_{\rho}$ decrease. At the further $\lambda \times \lambda_{n}$ increase caused by the $\lambda_{n}$ increase, the samples begin to split in the direction of rolling, and the film loses the continuity.
This means that the rolling action on the already oriented film results at some moment in destruction of the ordered structures and even in the mechanical rupture. The loosening of such sample structure is accompanied by significant reduction of the $\mathrm{Tg}$ to $55-58{ }^{\circ} \mathrm{C}$. The appearance of the ruptured films at rolling of the preliminary oriented films from PS has a different character compared with the PET films underwent to the same treatment [6]. Probably, this is connected with the nature of PS: the films made of this polymer are more brittle compared with the PET films, also, the PS macromolecules have irregular composition, and others.

As it was discussed above, the preliminary roll-treatment has the most effect on the consecutive orientation drawing. Because of this, it is necessary to discuss in details some aspects related to the roll-treatment. For example, what is the ratio between the compressing and extending forces. It is obvious that the film can be deformed by rolling it between a pair of rolls to a necessary $\lambda_{n}$ for one or more steps. If this is a continuous process, than it is possible to treat the film on the two, or three rolls machines with consecutively reducing clearance.

The data in Fig. 3 show the dependence of the stresses at compression between the flat planes $\left(\sigma_{\text {com }}\right)$, at compression between the not rotating rolls $\left(\sigma_{\mathrm{com}}{ }^{*}\right)$, and at the rolling between rotating rolIs $\left(\sigma_{n}\right)$ on the corresponding deformation, $\varepsilon$. At rolling, the $\varepsilon=(\lambda-1) \cdot 100 \%$. 


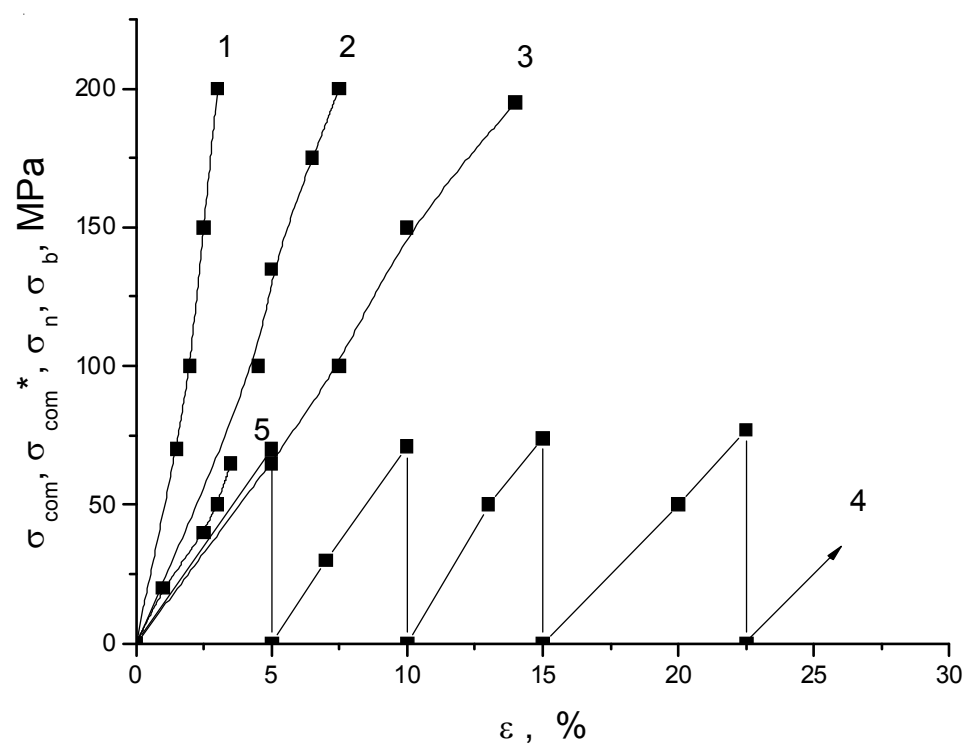

Fig. 3. Dependence of the stresses at compression between flat planes, $\sigma_{\text {com }}(1)$, at compression between not rotating rolls, $\sigma_{\text {com }} *(2)$, at rolling, $\sigma_{n}(3,4)$, and at elongation, $\sigma_{b}(5)$ on the corresponding film deformation, $\varepsilon$

It follows from comparison of the parameter values that the continuous rotation of the compressing film rolls (rolling) provides reduction of the compressing stress. Note, that at precise calculation of the compressing forces distribution along the curvature of the compressing rolls, the forces would be larger and the line 2 (Fig. 3), will come closer to the line 1 (Fig. 3 ).

However, due to the assumptions accepted for calculation of $\sigma_{n}$ and $\sigma_{\text {com }}{ }^{*}$ were the same, the better is to compare the data on curves 2 and 3 (Fig. 3). The lower values of $\sigma_{n}$ compared with $\sigma_{\text {com }}{ }^{*}$ can be explained by assuming that at film deformation, the tangential shearing and extending deformations play a big role. The change of the tensile stress, $\sigma_{b}$ in dependence on $\varepsilon$ is shown in Fig. 3 , curve 5 . It can be seen that the absolute values of $\sigma_{n}$ and $\sigma_{b}$ are practically coincide but the coincidence occurs only till $\varepsilon$ is below the yield point ( 3-5 \%).

At further elongation, the samples are mainly ruptured and only some of them show the 'neck' shape. In case of the rolling, the film deformation without forming the 'neck' can reach $100 \%$ or more. The comparison of curves 3 and 5 (Fig. 3) allows to assume that at rolling, the elongation deformation along the rolling direction takes place. The elongation in conditions of relatively low temperatures leads to significant polymer structure change: to destruction of the overloaded bonds, to creation of the more loose network [6], and so on.
All of this assists to the better consecutive orientational rolling as it is seen from Fig. 1 and 2 . From the data in Fig. 3, curve 3, it can be seen that to obtain films with optimal $\lambda_{n}$ or $\varepsilon=40-60 \%$, it is necessary to use significant forces. To obtain the same $\lambda$, it is possible to perform step-by-step rolling by continuously reducing the clearance between the rolls what is shown on the cyclogram 5, Fig. 3.

In the process of the experiments, it was found that each consecutive rolling step occurs with an approximately constant ratio $\Delta \sigma / \Delta \varepsilon$. This means that at least at $\lambda_{n}=1.4-1.6(\varepsilon=40$ $60 \%$ ), the rolling process can be divided into several steps either under constant $\sigma_{n}$ of each step (Fig. 3, curve 5) or under decreasing or increasing $\sigma_{n}$ by changing the $\varepsilon$ of each step. At small $\sigma_{n}$ values, to obtain the optimal final $\lambda_{n}$ values, it would be necessary to have many rolling steps for a certain samples or to have a set of many rolls for continuous rolling what is, probably, unwanted.

\section{Conclusions}

The performed investigations showed that the structure modification of such brittle film as the polystyrene one by the cold rolling is justified for the isotropic state and is not recommended for the oriented state. The step-by-step film rolling can reduce the internal mechanical stresses to achieve the optimal state of extension. The number 
of steps will be determined by the available equipment for the continuous modification process.

\section{REFERENCES}

1. Fujii Y., Morita H., Takahara A., Tanaka K. Mobility Gradient of Polystyrene in Films Supported on Solid Substrates. Adv. Polym. Sci., 2013, no. 252, pp. 1-28.

2. Harold W Wyckoff. Patent US 3405027 A, 1961. Kuleznev V.N., Vlasov S.V., Pavlov V.V., et al. The basic technology of plastics processing. Plastmassy, 1984, no. 1, p. 31. (in Russian).
3. Kuleznev V.N., Vlasov S.V., Pavlov V.V., et al. The basic technology of plastics processing. Plastmassy, 1984, no. 1, p. 31. (in Russian).

4. Vlasov S.V, Pavlov V.V., Kuleznev V.N., et al. Photochromism of a chiral dye for liquid crystal applications. Vysokomol. Soed., 1986, vol. A-28, no. 8, p. 1609.

5. Vlasov S.V., Kuleznev V.N. Oriented Phenomena in Polymers. 25th Europ. Conf. on Mak. Phys., St.-Pot, 1992, p. 124.

6. Vlasov S.V., Markov A.V., Sergeev V.V., et al. Orientatsionnye yavleniya pri proizvodstve izdeliy iz polimernykh materialov. Plastmassy, 1993, no. 5 , p. 34 .

\section{ВЛИЯНИЕ ПРОКАТКИ \\ НА ПОВЕДЕНИЕ ПОЛИСТИРОЛЬНОЙ ПЛЕНКИ}

\section{Анатолий Александрович Ольхов}

Кандидат технических наук, доцент,

старший научный сотрудник лаборатории перспективных композиционных материалов и технологий, РЭУ им. Г. В. Плеханова

aolkhov72@yandex.ru

Стремянный переулок, 36, 117997 г. Москва, Российская Федерация

Аннотация. Было исследовано влияние холодной прокатки на свойства изотропной и предварительно ориентированной полистирольных пленок. Было обнаружено, что модификацию пленок холодной прокаткой необходимо проводить только для изотропных пленок. Для достижения оптимального состояния прокатки и уменьшения побочных напряжений процесс должен осуществляться в несколько последовательных этапов.

Ключевые слова: холодная прокатка, изотропные полистирольные пленки, ориентированные полистирольные пленки, механические параметры, оптимальная прокатка. 